\title{
Effect of Particle Size of Iron Ore and Coke on Granulation Property of Quasi-Particle
}

\author{
Takayuki MAEDA, ${ }^{1{ }^{*}}$ Ryota KIKUCHI, ${ }^{2)}$ Ko-ichiro OHNO, ${ }^{1)}$ Masakata SHIMIZU1) and Kazuya KUNITOMO ${ }^{1)}$ \\ 1) Department of Materials Science \& Engineering, Kyushu University, 744 Motooka, Nishi-ku, Fukuoka, 819-0395 Japan. \\ 2) Formerly Graduate Student, Kyushu University. Now at Kobe Steel, Ltd., 744 Motooka, Nishi-ku, Fukuoka, 819-0395 Japan.
}

(Received on January 24, 2013; accepted on March 7, 2013)

\begin{abstract}
In order to evaluate quantitatively the distribution of coke breeze in the quasi-particles, the granulation experiment was carried out by using limonite iron ores and coke breeze, and the effects of particle size of iron ore and coke breeze on granulation properties were examined. Moreover, quantitative analysis of coke breeze in a quasi-particle was carried out. The results obtained are follows:

(1) Regardless of the brand of iron ores and existence of nuclei, the quasi-particle diameter became smaller when coke breeze was added and it became smaller when the particle size of coke breeze became larger. It is thought that the adhesion force by the liquid bridge became smaller because the contact angle between coke and water is larger than that between iron oxide and water.

(2) The coke contents of P-type quasi-particles without nuclei are almost constant regardless of its diameter because they are equally growing by adhering of the fine iron ore and coke breeze uniformly.

(3) In case of C-type quasi-particles containing nuclei, the adhering fines layer of C-type quasi-particles is growing by adhering of the fine iron ore and coke breeze uniformly until about $5 \mathrm{~mm}$ diameter of it. Consequently, the coke contents in the adhesion fines layer of C-type quasi-particle are almost constant regardless of its diameter. Moreover, it is thought that the peak of carbon content at over $5 \mathrm{~mm}$ diameter exists by coalescing of each granule.
\end{abstract}

KEY WORDS: carbon content; quasi-particle; granulation; limonite iron ore; coke breeze; iron ore sinter.

\section{Introduction}

Recently, the gradual depletion of high quality hematite iron ore in Western Australia has brought for an increase in limonite iron ores. The type of ores are inferior in sintering performance, and some of them such as Marra-mamba iron ore, have highly fine powder ratio and granulation property of them are inferior to other iron ores. Furthermore, limonite iron ores containing high combined water decrease the strength of sintered ores because many large cracks are formed during sintering. However, the increase in usage of limonite ore for raw material of sintering will cut down the cost of sinter since that ore is cheaper than other.

Therefore, it is important to develop the method granulating the fine particle efficiently because the limonite iron ore have highly fine powder ratio. Moreover, in recent years, corresponding to environmental problems such as global warming, $\mathrm{CO}_{2}$ emissions reduction has been an urgent subject also in the steel industry. The $\mathrm{CO}_{2}$ emissions in the steel industry occupied about $17 \%$ of the amount of domestic emissions, and ironmaking processes occupied about $70 \%$ of the $\mathrm{CO}_{2}$ emissions in a steelworks also in it. ${ }^{1)}$ In the sintering process, 4-6 mass $\%$ of coke breeze are added as the heat source. Therefore, if biomass can be used instead of

* Corresponding author: E-mail: maeda@zaiko.kyushu-u.ac.jp DOI: http://dx.doi.org/10.2355/isijinternational.53.1503 coke breeze or if the amount of coke breeze in quasi-particle can be reduced by appropriate arrangement in order to improve the combustion efficiency, it can be reduced the further $\mathrm{CO}_{2}$ emissions in the sintering process. Therefore, it is important to clarify the distribution of coke breeze in quasiparticle.

By the way, it is known that the distribution of the heat source (coke breeze, metallic iron etc.) in quasi-particles will greatly influence the combustion properties in a sintering process, and will influence the quality and productivity of iron ore sinter. Oyama et $a l^{2,3)}$ have reported that the productivity and reducibility of iron ore sinter were improved by coating coke breeze and limestone on the surface of quasiparticles. However, there is little research about distribution of the coke breeze in quasi-particles, and it is not clarified how the distribution of coke breeze in a quasi-particle is influenced by particle size of iron ore and coke breeze and difference of the granulation condition.

Therefore, in this study, in order to evaluate quantitatively the distribution of coke breeze in a quasi-particle, the granulation experiment was carried out by using limonite iron ores and coke breeze and the effects of particle size of iron ore and coke breeze on granulation properties were examined. Moreover, quantitative analysis of coke breeze in a quasi-particle was performed. 


\section{Sample and Experiment}

Figure 1 shows the distribution of coke breeze in quasiparticle classified by Hida et ll $^{4)}$ Pellet-type (P-type) quasi-particle is composed by fine iron ore and coke breeze. Composite-type (C-type) quasi-particle is composed by coarse iron ore (nuclei particle) and the adhering fines layer including fine iron ore and coke. Single-type (S-type) is composed by coarse coke (nuclei particle) and the adhering fines layer including fine iron ore and coke. In this study, the granulation experiments were carried out about P-type and C-type that is associated with the combustion rate of the coke breeze.

Pisolite iron ore (ore R) and Marra-mamba iron ore (ore $\mathrm{M})$ were used for granulation experiment. In the granulation experiment for P-type, particle size of ore $\mathrm{R}$ and ore $\mathrm{M}$ was $-0.125 \mathrm{~mm}$ and $-0.25 \mathrm{~mm}$, respectively and particle size of coke breeze was $-0.125 \mathrm{~mm}$ and $-0.25 \mathrm{~mm}$. Mixing ratio of fine iron ore and coke was $96: 4$ in weight ratio. In the granulation experiment for $\mathrm{C}$-type, ore $\mathrm{R}$ and ore $\mathrm{M}$ having 1-3.35 mm particle size were used for nuclei particles and particle size of both fine iron ore was $-0.25 \mathrm{~mm}$, and particle size of coke breeze was $-0.125 \mathrm{~mm}$ and $-0.25 \mathrm{~mm}$. Mixing ratio of nuclei particle, fine iron ore and coke breeze was $48: 48: 4$ in weight ratio.

The granulator was a disc type pelletizer featuring a rotating tire of $50 \mathrm{~cm}$ dia., $15 \mathrm{~cm}$ width. The speed of revolution in granulation was $40 \mathrm{rpm}$, and granulation time was $8 \mathrm{~min}-$ utes. In case of P-type, adding moisture for ore $\mathrm{R}$ and ore $\mathrm{M}$ was 55 and $60 \mathrm{cc}$ (18.0 and 16.7 mass\%), respectively.

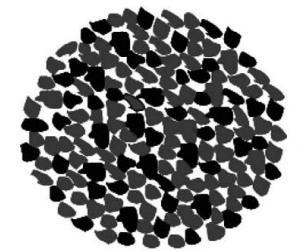

$P$ (Pellet)-type

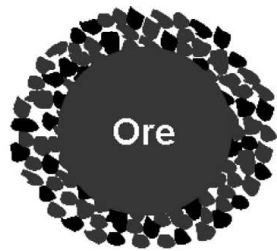

C(Composite)-type

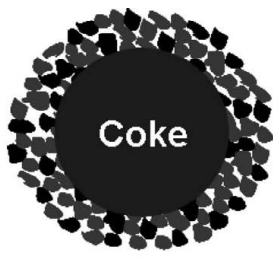

S(Single)-type
Fig. 1. Classification of quasi-particles of raw mix. ${ }^{4}$
In case of C-type, adding moisture for ore $\mathrm{R}$ and ore $\mathrm{M}$ was 60 and $50 \mathrm{cc}$ (16.7 and 14.3 mass \%), respectively. The addition of moisture was conducted by the same method in previous study. ${ }^{5,6)}$ The volume of sample used for the granulation experiment was $148 \mathrm{cc}$ both P-type and C-type.

After granulation, granulated particles were screened to be the particle size $1-2 \mathrm{~mm}, 2-4 \mathrm{~mm}, 4-5.6 \mathrm{~mm}, 5.6-8 \mathrm{~mm}$, $8-9.5 \mathrm{~mm}, 9.5-11.2 \mathrm{~mm}$ and $11.2-13.2 \mathrm{~mm}$, and the particle diameter distributions of granule were measured. Carbon contents of quasi-particle were measured by carbon analyzer (HORIBA EMIA-110). Moreover, coke contents of Ptype quasi-particle and adhering fines layer in C-type quasiparticle were measured by image analysis. In image analysis, coke contents were measured by using 15-30 pictures per sample, then coke contents of sample were determined by using the average of them.

\section{Results and Discussion}

\subsection{Granulation of P-type}

Figure 2 shows the overall view of granulated particle. Upper parts of this figure show the results of ore R and lower parts of this figure show the results of ore M. From the left of this figure, the results of no coke breeze adding, added coke breeze size $-0.125 \mathrm{~mm}$ and $-0.25 \mathrm{~mm}$ were shown, respectively.

From this figure, when coke breeze was added, it was found that the quasi-particle diameter became smaller regardless of the brand of iron ore. These granules were screened and particle diameter distribution was measured.

Figures 3 and 4 show the particle diameter distribution of granule made from ore $\mathrm{R}$ and ore $\mathrm{M}$, respectively. From the left of these figures, the results of no coke breeze adding, added coke breeze size $-0.125 \mathrm{~mm}$ and $-0.25 \mathrm{~mm}$ were shown, respectively.

As shown in Fig. 3, when only ore $\mathrm{R}$ was used, a large number of quasi-particles having $8.0-11.2 \mathrm{~mm}$ diameter were formed, but $-4.0 \mathrm{~mm}$ was hardly formed. When -0.125 $\mathrm{mm}$ coke breeze was added to ore $\mathrm{R}$, a large number of quasiparticles having $4.0-8.0 \mathrm{~mm}$ diameter were formed, but the
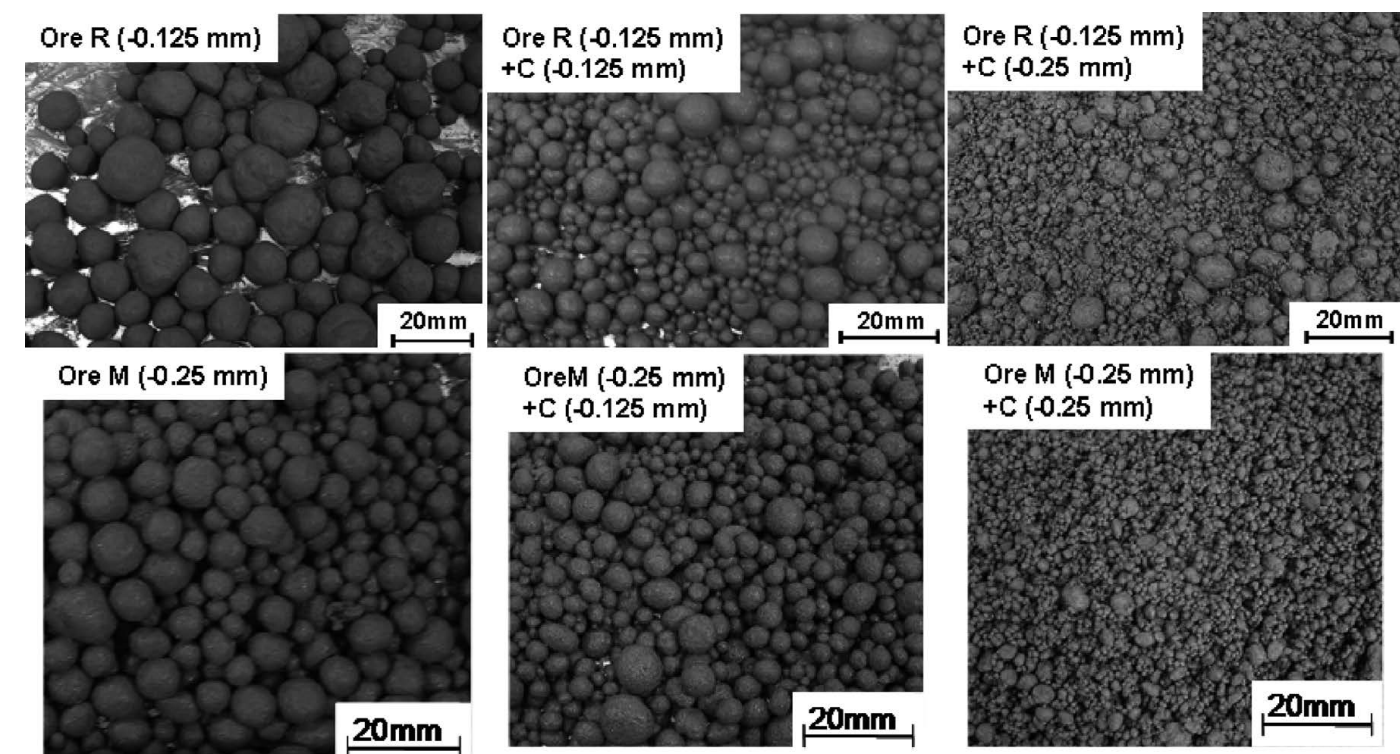

Fig. 2. Overall view of granulated particles. 


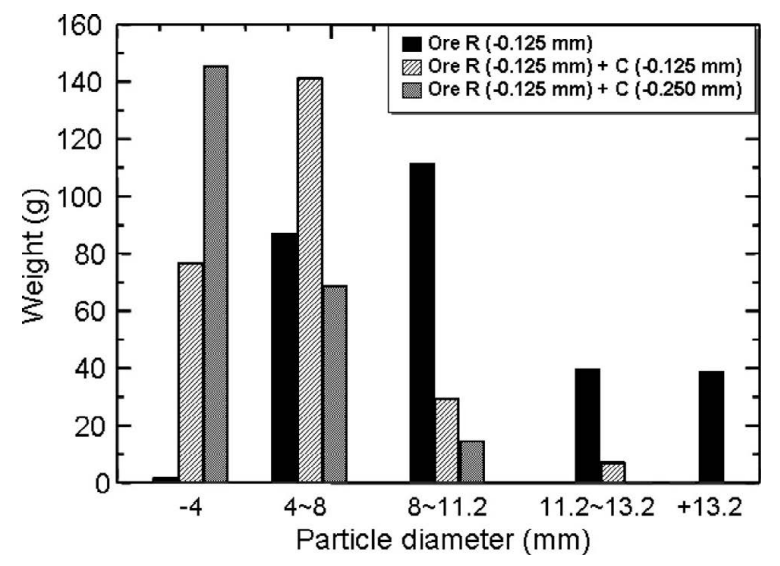

Fig. 3. Particle size distribution of granules using Ore R.

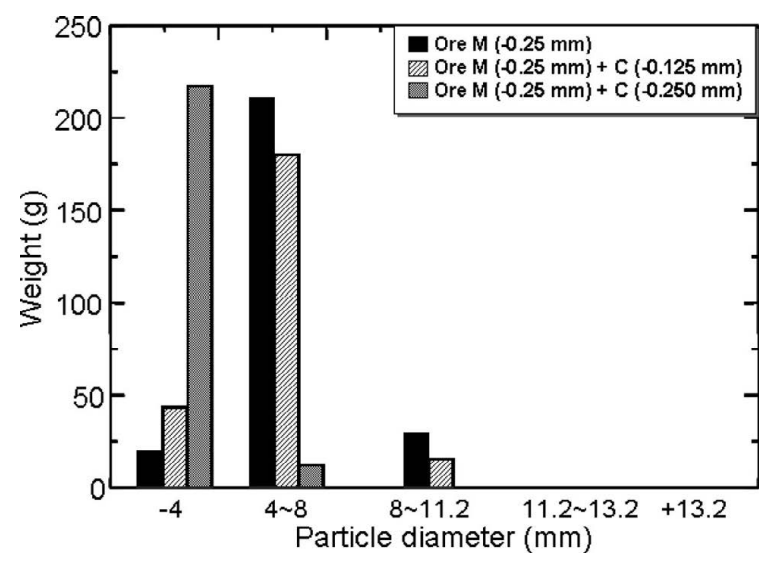

Fig. 4. Particle size distribution of granules using Ore M.

quasi-particle having over $13.2 \mathrm{~mm}$ diameter was not formed. When $-0.25 \mathrm{~mm}$ coke breeze was added to ore $\mathrm{R}$, a large number of quasi-particles having $-4.0 \mathrm{~mm}$ diameter were formed, but the quasi-particle having over $11.2 \mathrm{~mm}$ diameter was not formed. Therefore, it was found that the granule diameter became smaller when coke breeze was added to ore $\mathrm{R}$, and it was found that the granule diameter became smaller when the particle size of adding coke breeze became larger.

As shown in Fig. 4, When only ore $\mathrm{M}$ was used, a large number of quasi-particles having $4.0-8.0 \mathrm{~mm}$ diameter were formed, but the quasi-particles having over $11.2 \mathrm{~mm}$ diameter were not formed. Also when $-0.125 \mathrm{~mm}$ coke breeze was added to ore $\mathrm{M}$, a large number of quasi-particles having 4.0-8.0 $\mathrm{mm}$ diameter were formed, but the quasi-particles having over $11.2 \mathrm{~mm}$ diameter were not formed. When -0.25 $\mathrm{mm}$ coke breeze was added to ore $\mathrm{M}$, a large number of quasiparticles having $-4.0 \mathrm{~mm}$ diameter were formed, but the quasi-particles having over $8.0 \mathrm{~mm}$ diameter were not formed. Therefore, in case of ore $\mathrm{M}$ as well as ore $\mathrm{R}$, the granule diameter became smaller when coke breeze was added, and the granule diameter became smaller when the particle size of coke breeze became larger.

Consequently, regardless of the brand of iron ore, it was found that the granule diameter became smaller when coke breeze was added and it became smaller when the particle size of coke breeze became larger. By the way, it is thought that the main adhesive force between the powder particles is van der Waals force, electrostatic force and liquid bridge

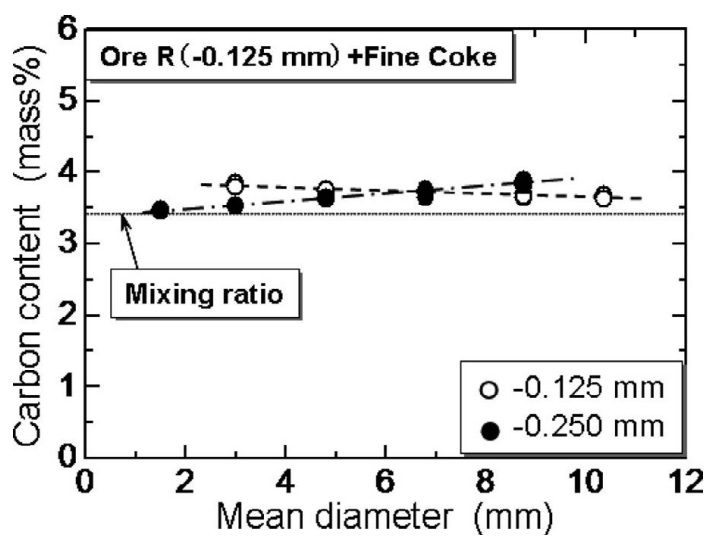

Fig. 5. Carbon content of granulated particle.

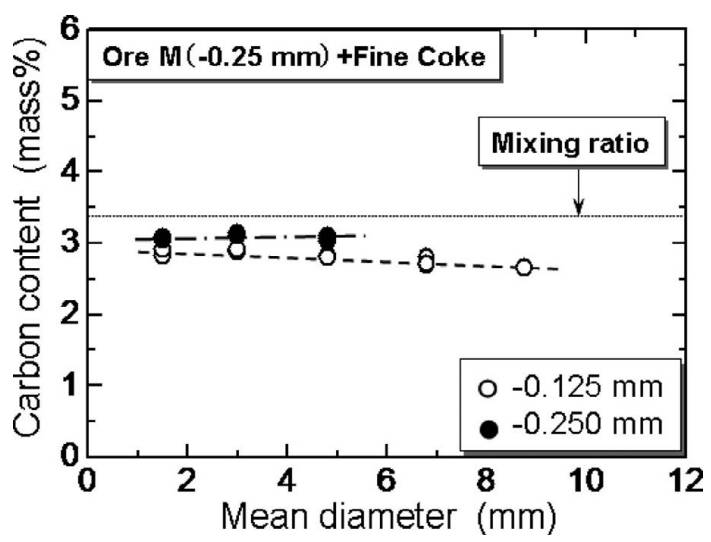

Fig. 6. Carbon content of granulated particle.

force. The liquid bridge force is considered to act dominantly because moisture is added in the granulation process of sintered iron ore. The adhesion force ${ }^{7,8)}$ between particles by liquid bridge is expressed by Eq. (1).

$$
F_{c}=-2 \pi \gamma_{l v} d_{p} \cos \theta
$$

$F_{c}:$ adhesion force $(\mathrm{N})$

$d_{p}:$ particle diameter $(\mathrm{m})$

$\gamma_{l v}:$ surface tension of liquid $(\mathrm{N} / \mathrm{m})$

$\theta:$ contact angle (degree)

Oyama et al. $^{2)}$ have reported that the contact angle between coke and water is larger than that between iron oxide and water. Therefore, it is thought that the quasi-particle diameter became smaller because the adhesion force $F_{c}$ by the liquid bridge expressed by Eq. (1) became smaller since the contact angle becomes larger by adding coke breeze. In addition, when the particle size of coke breeze becomes larger, it is thought that the quasi-particle diameter became smaller because the volume of the water bridge decreases with decreasing the contact point among particles. ${ }^{9)}$

Figures 5 and $\mathbf{6}$ show the relationship between carbon contents in granules measured by carbon analyzer and mean diameter of granules made from ore $\mathrm{R}$ and ore $\mathrm{M}$, respectively. In addition, in these figures, the carbon contents calculated from adding coke breeze are also shown for comparison.

From Fig. 5, it was found that the carbon contents of granules a little decreased with increasing the mean diameter of granules when $-0.125 \mathrm{~mm}$ coke breeze was added to 
ore R. On the other hand, it was found that the carbon contents of granules a little increased with increasing the mean diameter of granules when $-0.25 \mathrm{~mm}$ coke was added to ore R. Moreover, it was found that the carbon contents of granules measured by carbon analyzer and calculated from additive coke breeze were almost the same in all particle size. It is considered that this is because both fine iron ore and coke breeze are adhering to P-type quasi-particles approximately at the same time during granulation process.

From Fig. 6, it was found that the carbon contents of granules a little decreased with increasing the mean diameter of granules when $-0.125 \mathrm{~mm}$ coke breeze was added to ore M. On the other hand, it was found that the carbon contents of granules took approximately constant value regardless of the mean diameter of granules when $-0.25 \mathrm{~mm}$ coke was added to ore M. Moreover, it was found that the carbon contents of granules measured by carbon analyzer were a little small than that of calculated value from additive coke breeze, but the difference of these values was very small in all particle size.

Figure 7 shows the relationship between coke contents in granules measured by image analysis and mean diameter of granules made from ore R. Although measuring methods were different, the tendency between carbon contents mea-

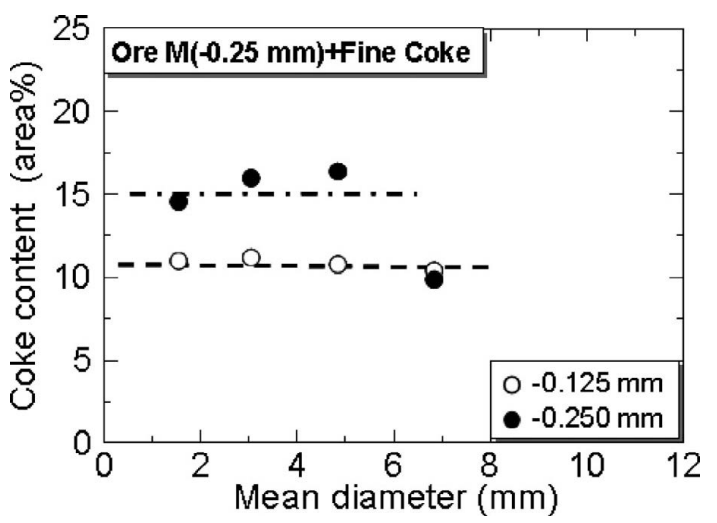

Fig. 7. Coke content of adhering fines layer in quasi-particle measured by image analysis. sured by image analysis and mean diameter of granules coincided with that of carbon analyzer method as shown in Fig. 6.

As mentioned above, quasi-particle diameter of P-type becomes smaller when the diameter of added coke breeze becomes larger. Furthermore, quasi-particle diameter of Ptype becomes smaller because the adhesion force by the liquid bridge becomes smaller when coke breeze was added. However, it is thought that the coke breeze contents containing in P-type quasi-particle are almost constant regardless of its diameter because P-type quasi-particles are equally growing with adhering of the fine iron ore and coke breeze uniformly.

\subsection{Granulation of C-type}

Figure 8 shows the overall view of granulated particle. Upper parts of this figure show the results of ore R and lower parts of this figure show the results of ore M. From the left of this figure, the results of no coke breeze adding, added coke breeze size $-0.125 \mathrm{~mm}$ and $-0.25 \mathrm{~mm}$ were shown, respectively.

From this figure, as in the case of the P-type quasi-particle using only fine iron ore, it was found that the quasi-particle diameter became smaller regardless of the brand of iron ore when coke was added. These granules were screened and particle diameter distribution was measured.

Figures 9 and 10 show the particle diameter distribution of granule made from ore $\mathrm{R}$ and ore $\mathrm{M}$, respectively. From the left of these figures, the results of no coke breeze adding, added coke breeze size $-0.125 \mathrm{~mm}$ and $-0.25 \mathrm{~mm}$ were shown, respectively.

As shown in Fig. 9, when ore $\mathrm{R}$ was used, the quasiparticles having over $9.5 \mathrm{~mm}$ diameter were not formed in all experimental conditions. When only iron ore was used, the quasi-particles having $8.0-9.5 \mathrm{~mm}$ diameter were a little formed and a large number of quasi-particles having 5.6-8.0 $\mathrm{mm}$ diameter were formed, but the amount of formation of quasi-particles having under $5.6 \mathrm{~mm}$ diameter also decreased as granule diameter became smaller. When $-0.125 \mathrm{~mm}$ coke breeze was added to ore $\mathrm{R}$, the quasi-particles having over

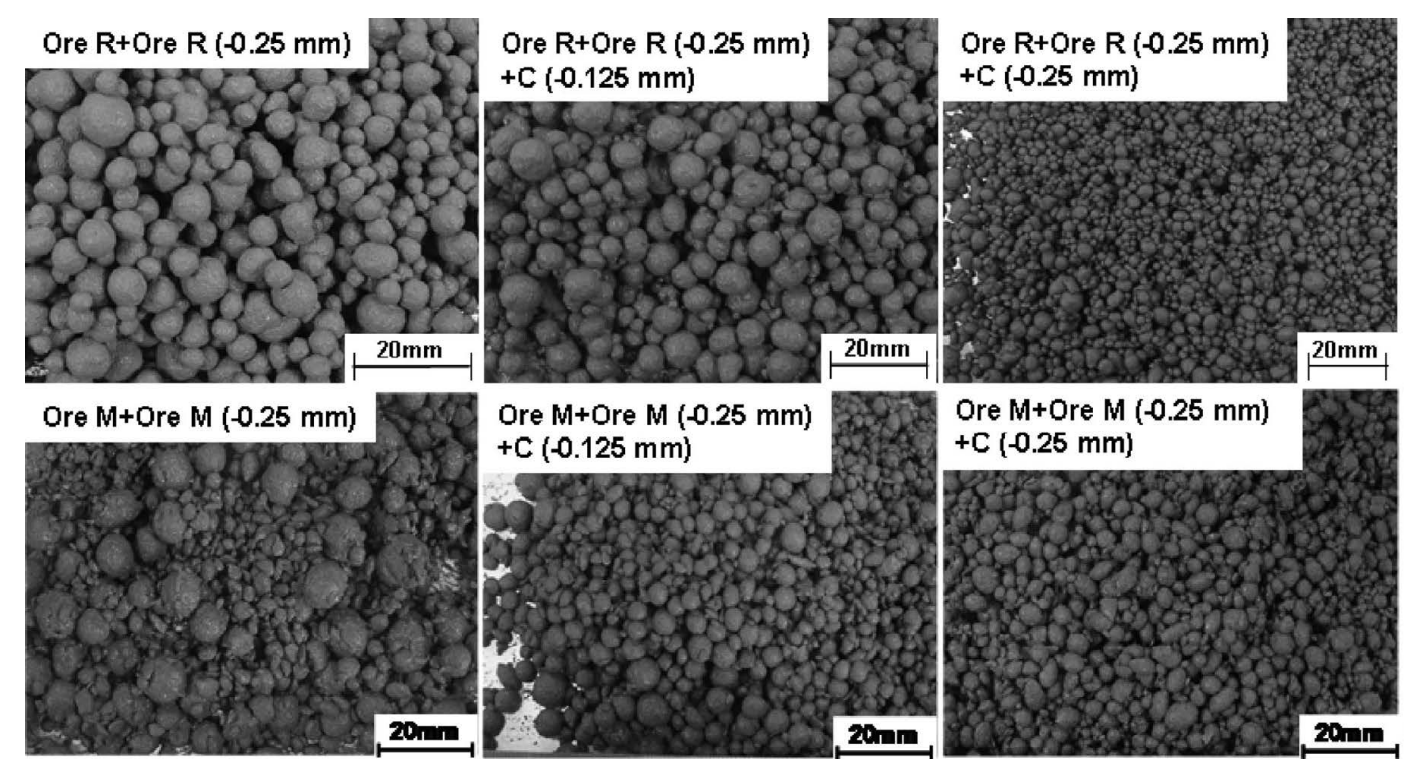

Fig. 8. Overall view of granulated particles. 


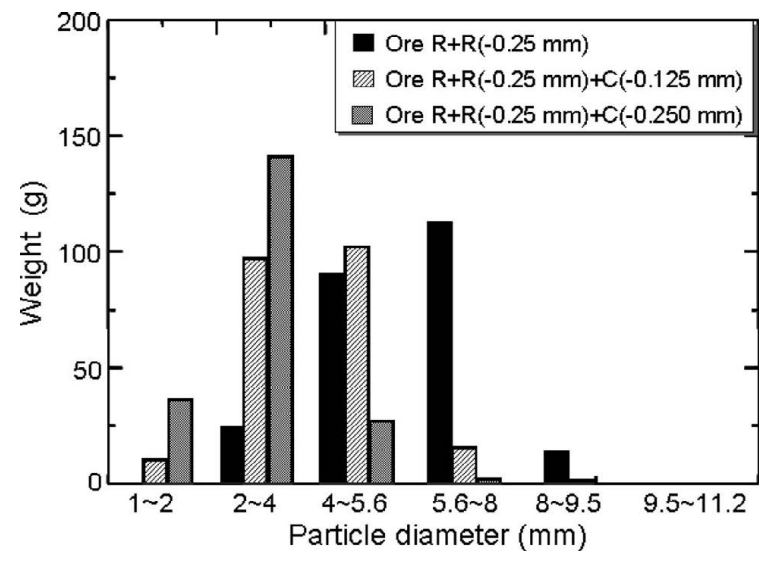

Fig. 9. Particle size distribution of granules using Ore R.

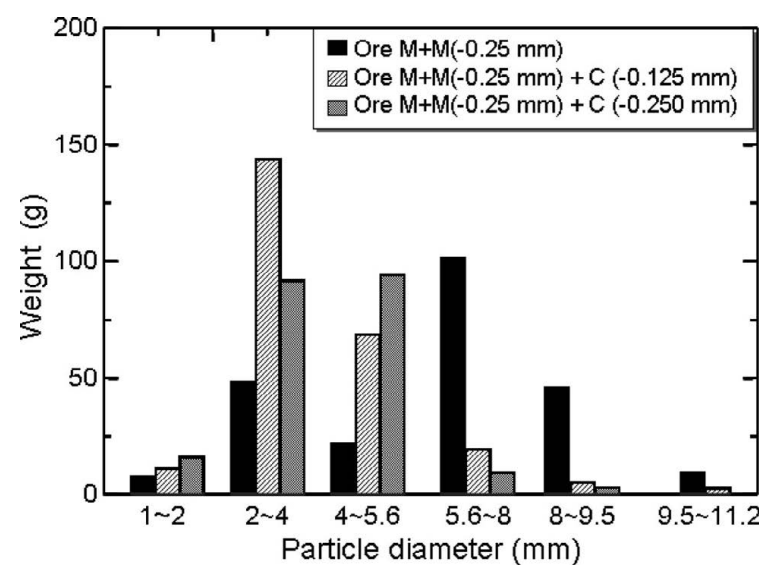

Fig. 10. Particle size distribution of granules using Ore M.

$8.0 \mathrm{~mm}$ diameter were hardly formed and a large number of quasi-particles having 4.0-5.6 $\mathrm{mm}$ diameter were formed, but the amount of formation of quasi-particles having under $4.0 \mathrm{~mm}$ diameter was decreased as granule diameter became smaller. When $-0.25 \mathrm{~mm}$ coke breeze was added to ore $\mathrm{R}$, a large number of quasi-particles having 2.0-4.0 mm diameter were formed but the number of formation of other diameter granules was very small. These showed that the quasi-particles diameter became smaller when coke breeze was added and when the particle size of added coke breeze became larger.

As shown in Fig. 10, when only ore $\mathrm{M}$ was used, a large number of quasi-particles having 5.6-8.0 $\mathrm{mm}$ diameter was formed, but the number of formation of quasi-particles having under $4 \mathrm{~mm}$ diameter was small. When $-0.125 \mathrm{~mm}$ coke breeze was added to ore $\mathrm{M}$, a large number of quasi-particles having 2.0-5.6 mm diameter was formed, but the number of formation of quasi-particles having over $5.6 \mathrm{~mm}$ diameter was very small. When $-0.25 \mathrm{~mm}$ coke breeze was added to ore $\mathrm{M}$, a large number of quasi-particles having $2.0-5.6 \mathrm{~mm}$ diameter was formed, but the number of formation of quasiparticles having over $5.6 \mathrm{~mm}$ diameter was very small. In the case of ore $M$ as well as ore $R$, these showed that the quasi-particles diameter became smaller when coke breeze was added and when the particle size of added coke breeze became larger.

From the results above mentioned, as well as P-type quasiparticles without nuclei, it was found that the C-type quasi-

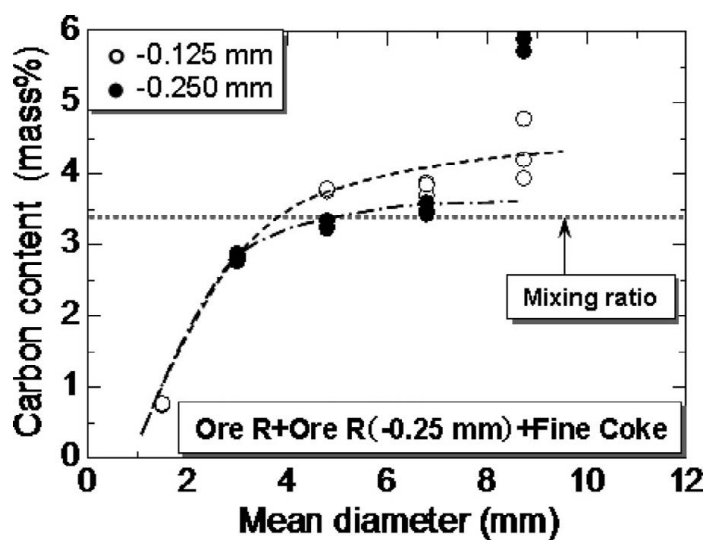

Fig. 11. Carbon content of granulated particle.

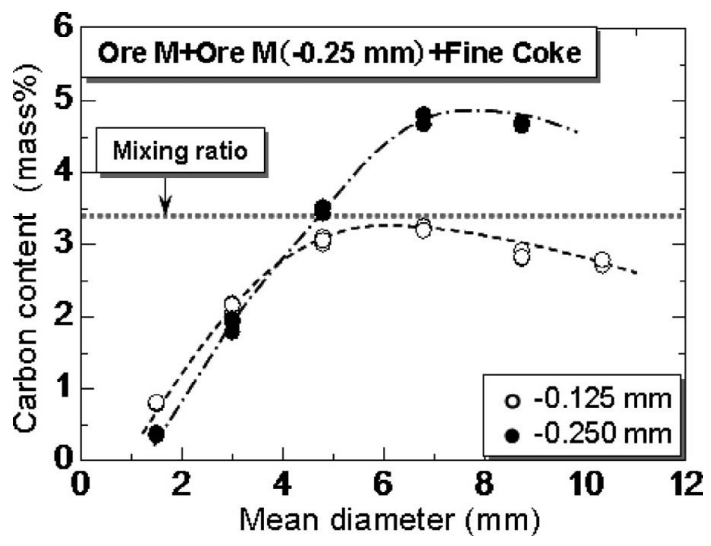

Fig. 12. Carbon content of granulated particle.

particles with nuclei became smaller when coke breeze was added regardless of the brand of iron ore. Furthermore, it was found that the C-type quasi-particles diameter became smaller when the particle size of added coke breeze became larger. As well as granulation without nuclei, it is thought that the quasi-particle diameter became smaller because the adhesion force $F_{c}$ by the liquid bridge expressed by Eq. (1) became smaller since the contact angle became larger by adding coke breeze.

Figures 11 and 12 show the relationship between carbon contents in granules measured by carbon analyzer and mean diameter of granules made from ore $\mathrm{R}$ and ore $\mathrm{M}$, respectively. In addition, in these figures, the carbon contents calculated from adding coke breeze are also shown for comparison.

From Fig. 11, when coke breeze was added to ore R, it was found that the carbon contents of granules increased with increasing particle diameter of granules. In the case of P-type quasi-particle without nuclei, both fine iron ore and coke breeze are adhering to P-type quasi-particle approximately at the same time during granulation process. In contrast, in the case of C-type quasi-particle with nuclei, it was found that the carbon contents of granules were very small when the granule diameter was small because the adhering fines layer was thin in early stages of granulation, but the carbon contents of granules also increased with increasing granule diameter because the adhering fines layer became thicker by progress of granulation.

From Fig. 12, when coke breeze was added to ore M, the 

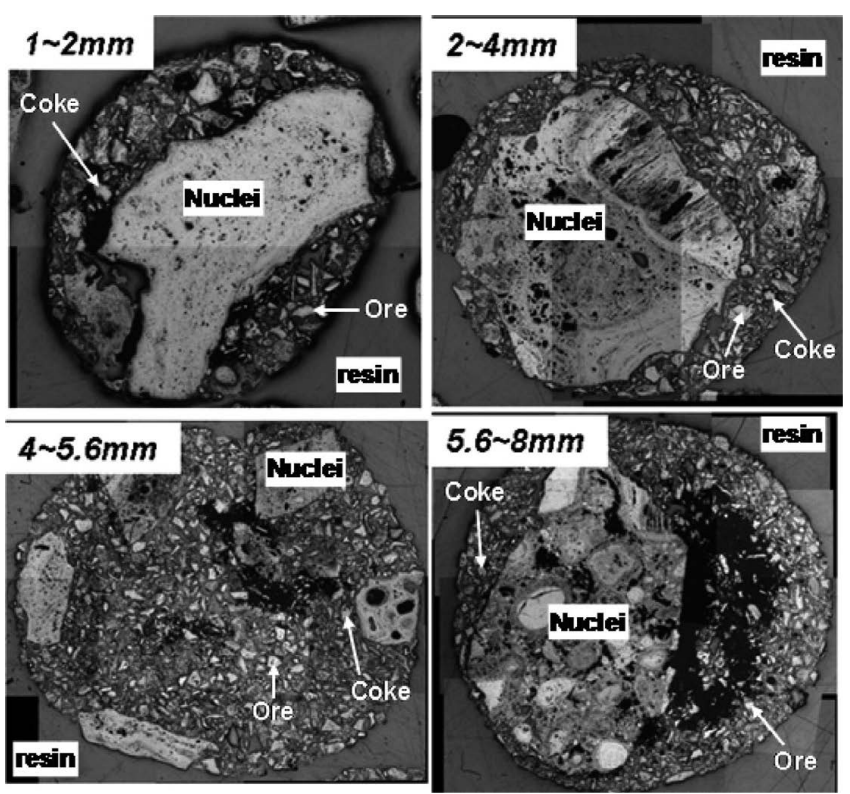

Fig. 13. Cross sectional view of quasi-particles (Ore R).

carbon contents of granules increased until about $6 \mathrm{~mm}$ of granule diameter, but the carbon contents of granules decreased when granule diameter became over $6 \mathrm{~mm}$. Therefore, when ore $\mathrm{R}$ was used for granulation, it was found that the peak existed between carbon contents and particle diameter of quasi-particle as shown in Fig. 12.

Figure 13 shows the cross sectional view of C-type quasi-particles that granulated using ore $\mathrm{R}$ and $-0.25 \mathrm{~mm}$ coke breeze. From this figure, it was found that the adhering fines layer was thickening with becoming the granule diameter larger. Consequently, since the adhesion fines layer including coke breeze became thicker by becoming granule diameter larger, the carbon contents of granules were increased with thickening the adhesion fines layer because the coke breeze in quasi-particles increased relatively.

In addition, when ore $\mathrm{M}$ was used, when two or more nuclei particles exist in large diameter quasi-particle, the amount of coke breeze in large diameter quasi-particle decreases since the adhesion fines layer becomes thin. Therefore, as shown in Fig. 12, the peak existed between carbon contents and quasi-particles.

By the way, in the case of P-type quasi-particle, it is thought that the carbon contents of granules are not dependent on its diameter because the coke breeze ratio in granule is constant from the early stage of granulation when nuclei particle does not exist in quasi-particle.

Figures 14 and 15 show the relationship between coke contents in granules measured by image analysis and mean diameter of granules made from ore $\mathrm{R}$ and $\mathrm{M}$, respectively. As well as P-type quasi-particle, as shown in these figures it was found that the coke contents in the adhesion fines layer of C-type quasi-particle were almost constant regardless of the quasi-particle diameter.

Therefore, in the case of C-type quasi-particle, the carbon contents of granules became small because the adhering fines layer was thin in early stage of granulation, but the carbon content of granule increased with thickening the adhering fines layer containing coke breeze because the adhesion fines layer became thicker by becoming the granule diame-

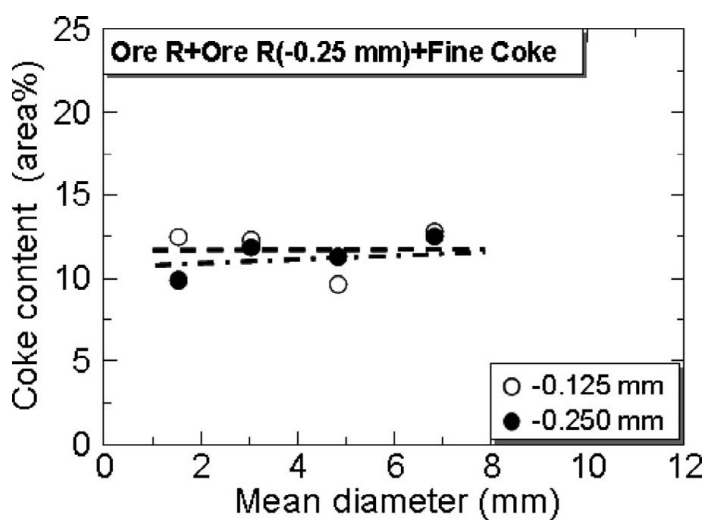

Fig. 14. Coke content of adhering fines layer in quasi-particle measured by image analysis.

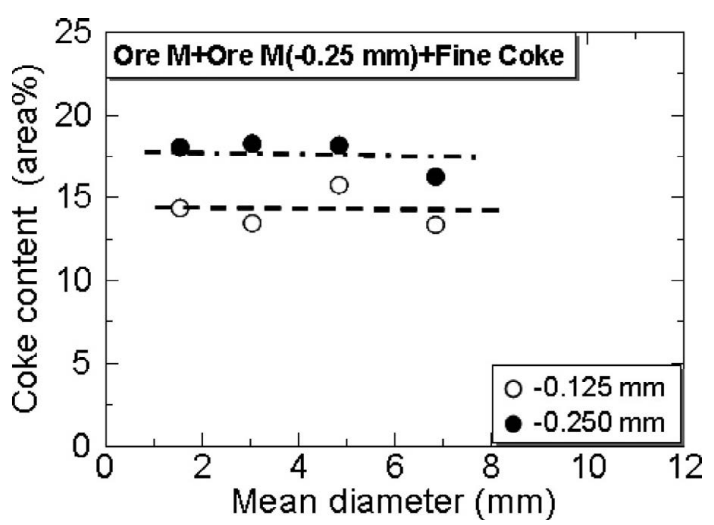

Fig. 15. Coke content of adhering fines layer in quasi-particle measured by image analysis.

ter larger. Moreover, it is thought that the adhering fines layer of C-type quasi-particle is growing with adhering of the fine iron ore and coke breeze uniformly because the coke contents of the adhesion fines layer are constant as well as P-type.

As mentioned above, it is thought that the growth process of the adhesion fines layer of the C-type quasi-particle is the same as the growth process of the P-type quasi-particle. Then, the carbon contents of the adhesion fines layer in the C-type quasi-particle were estimated by using simple model when ore $\mathrm{M}$ was used.

When the nuclei particle and the fines are assumed to be sphere, and when the fine iron ore and coke breezes adhere around the nuclei particle uniformly, the carbon content in the adhering fines layer of the C-type quasi-particle is calculated by the following Eq. (5).

$$
\begin{gathered}
m_{0}=\frac{\pi d_{0}^{3}}{6} \rho_{\text {Ore }} \\
m_{i}=\frac{\pi}{6}\left(d_{i}^{3}-d_{0}^{3}\right) \rho_{b} \\
m_{c}=\alpha m_{i} C_{\text {coke }} \\
C_{c}=\frac{m_{c}}{m_{0}+m_{i}} \times 100
\end{gathered}
$$

$C_{\text {coke }}$ : Carbon composition of coke (-)

$C_{c}$ : Carbon content (mass\%)

$d_{0}$ : Diameter of nuclei $(\mathrm{m})$ 
$d_{i}:$ Diameter of adhering fines layer (m)

$m_{0}$ : Weight of nuclei $(\mathrm{kg})$

$m_{c}$ : Weight of carbon $(\mathrm{kg})$

$m_{i}$ : Weight of adhering fines layer $(\mathrm{kg})$

$\alpha$ : Mixture ratio of coke (-)

$\rho_{\text {Ore }}:$ True density o iron ore $\left(\mathrm{kg} / \mathrm{m}^{3}\right)$

$\rho_{b}$ : Apparent density of adhering fines layer $\left(\mathrm{kg} / \mathrm{m}^{3}\right)$ Next values were used in this calculation. : $C_{\text {coke }}$ was 0.85 $(-), \rho_{\text {ore }}$ was $4.0 \times 10^{3}\left(\mathrm{~kg} / \mathrm{m}^{3}\right), \rho_{b}$ was $3.22 \times 10^{3}\left(\mathrm{~kg} / \mathrm{m}^{3}\right)$, and $\alpha$ was $0.4(-)$. When assuming that the quasi-particles are growing every $0.1 \mathrm{~mm}$, the carbon contents of the C-type quasi-particle are calculated by the Eq. (5) with substituting the value of nuclei diameter of 1.0 and $3.5 \mathrm{~mm}$ which was minimum and maximum diameter of it respectively to the Eq. (2).

The results of calculation in case of fine iron ores having $-0.125 \mathrm{~mm}$ and $-0.25 \mathrm{~mm}$ diameter were shown in Figs. 16 and 17, respectively. The measured carbon contents were also shown in Figs. 16 and 17 for comparison with calculated carbon contents. In these figures, the calculated carbon contents in case of nuclei having $1.0-3.35 \mathrm{~mm}$ diameter are shown by the range with the slanted line.

From these figures, it was found that the measured carbon contents were within the limits of calculated values until about $5 \mathrm{~mm}$ of quasi-particle diameter regardless of diameter of fine iron ore and coke breeze. Therefore, in the case

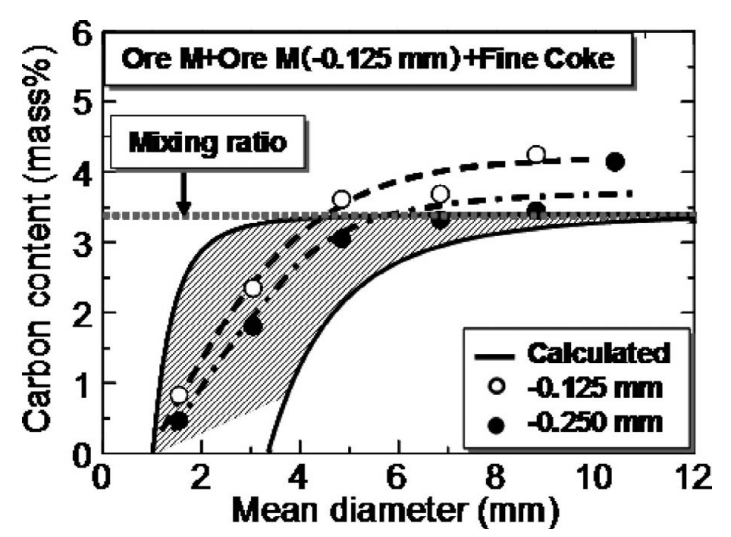

Fig. 16. Comparison of calculated carbon contents with observed data.

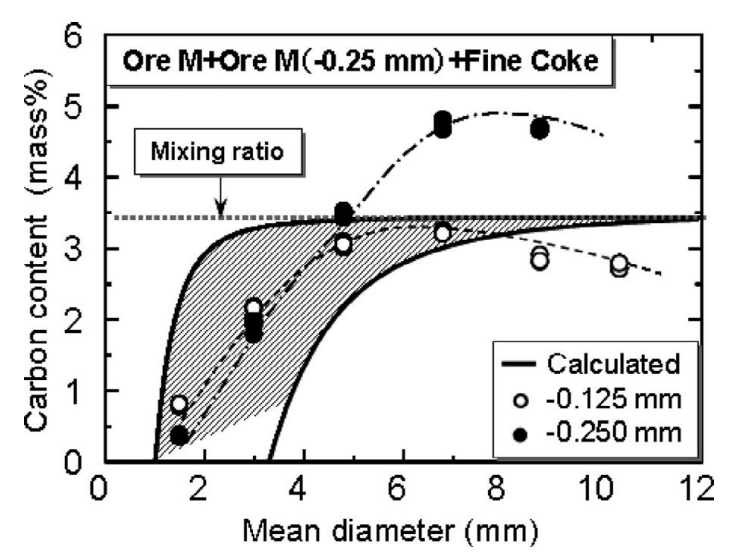

Fig. 17. Comparison of calculated carbon contents with observed data. of C-type quasi-particle, the granule is growing with adhering of the fine iron ore and coke breeze uniformly until about $5 \mathrm{~mm}$ diameter of it as well as P-type, and the granule is growing to over $5 \mathrm{~mm}$ diameter by coalescing each other.

As mentioned above, as well as P-type quasi-particles without nuclei, the diameter of $\mathrm{C}$-type quasi-particle with nuclei becomes smaller when coke breeze size becomes larger. Furthermore, the diameter of C-type quasi-particle becomes smaller because the adhesion force by the liquid bridge became smaller when coke breeze is added. In addition, the adhering fines layer of C-type quasi-particles is growing by adhering of the fine iron ore and coke breeze uniformly until about $5 \mathrm{~mm}$ diameter of it. Consequently, it is thought that the coke content in the adhesion fines layer of C-type quasi-particle is almost constant regardless of its diameter. Moreover, it is thought that the peak of carbon content at over $5 \mathrm{~mm}$ diameter exists by coalescing of each granule.

\section{Conclusion}

In order to evaluate quantitatively the distribution of coke breeze in the quasi-particles, the granulation experiment was carried out by using limonite iron ores and coke breeze, and the effects of particle size of iron ore and coke breeze on granulation properties were examined. Moreover, quantitative analysis of coke breeze in a quasi-particle was carried out. The results obtained are follows:

(1) Regardless of the brand of iron ores and existence of nuclei, the quasi-particle diameter became smaller when coke breeze was added and it became smaller when the particle size of coke breeze became larger. It is thought that the adhesion force by the liquid bridge became smaller because the contact angle between coke and water is larger than that between iron oxide and water.

(2) The coke contents of P-type quasi-particles without nuclei are almost constant regardless of its diameter because they are equally growing by adhering of the fine iron ore and coke breeze uniformly.

(3) In case of C-type quasi-particles containing nuclei, the adhering fines layer of C-type quasi-particles is growing by adhering of the fine iron ore and coke breeze uniformly until about $5 \mathrm{~mm}$ diameter of it. Consequently, the coke contents in the adhesion fines layer of C-type quasi-particle are almost constant regardless of its diameter. Moreover, it is thought that the peak of carbon content at over $5 \mathrm{~mm}$ diameter exists by coalescing of each granule.

\section{REFERENCES}

1) M. Hammyo: Bull. Iron Steel Inst. Jpn., 12 (2007), 456.

2) N. Oyama, K. Igawa, K. Takeda, T. Ariyama and T. Jinno: Tetsu-toHagané, 90 (2004), 546.

3) N. Oyama, H. Sato, K. Takeda, T. Ariyama, S. Masumoto, T. Jinno and N. Fujii: ISIJ Int., 45 (2005), 817.

4) H. Hida, M. Sasaki, T. Enokido, Y. Umezu, T. Iida and R. Uno: Tetsuto-Hagané, 68 (1982), 400.

5) T. Maeda, C. Fukumoto, T. Matsumura, K. Nishioka and M. Shimizu: ISIJ Int., 45 (2005), 477.

6) T. Maeda, K. Nishioka and M. Shimizu: ISIJ Int., 49 (2009), 625

7) R. H. Fishrer: J. Agric. Sci., 16 (1926), 492.

8) S. Sakashita: Funtai Process Sekkei, Kogyochosakai, Tokyo, (1999), 42.

9) S. Kawachi and S. Kasama: Tetsu-to-Hagané, 94 (2008), 475. 